\title{
Injector-Amplifier Design for Tabletop Ne-Like X-Ray Lasers
}

\author{
J. Dunn, A.L. Osterheld, A.Y. Faenov, T.A. Pikuz, V.N. \\ Shlyaptsev
}

This article was submitted to $8^{\text {th }}$ International Conference on X-Ray Lasers, Aspen, CO, May 27-31, 2002

\section{October 7, 2002}

U.S. Department of Energy

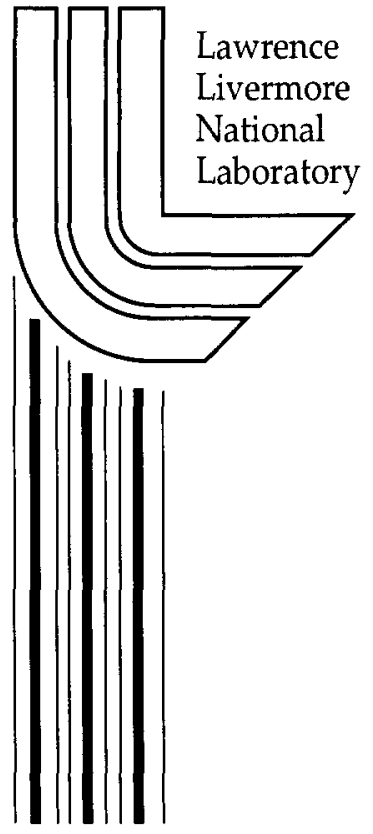


This document was prepared as an account of work sponsored by an agency of the United States Government. Neither the United States Government nor the University of California nor any of their employees, makes any warranty, express or implied, or assumes any legal liability or responsibility for the accuracy, completeness, or usefulness of any information, apparatus, product, or process disclosed, or represents that its use would not infringe privately owned rights. Reference herein to any specific commercial product, process, or service by trade name, trademark, manufacturer, or otherwise, does not necessarily constitute or imply its endorsement, recommendation, or favoring by the United States Government or the University of California. The views and opinions of authors expressed herein do not necessarily state or reflect those of the United States Government or the University of California, and shall not be used for advertising or product endorsement purposes.

This is a preprint of a paper intended for publication in a journal or proceedings. Since changes may be made before publication, this preprint is made available with the understanding that it will not be cited or reproduced without the permission of the author.

This report has been reproduced directly from the best available copy.

Available electronically at http://www.doc.gov/bridge

Available for a processing fee to U.S. Department of Energy

And its contractors in paper from

U.S. Department of Energy

Office of Scientific and Technical Information

P.O. Box 62

Oak Ridge, TN 37831-0062

Telephone: (865) 576-8401

Facsimile: (865) 576-5728

E-mail: reports@adonis.osti.gov

Available for the sale to the public from

U.S. Department of Commerce

National Technical Information Service

5285 Port Royal Road

Springfield, VA 22161

Telephone: (800) 553-6847

Facsimile: (703) 605-6900

E-mail: orders@ntis.fedworld.gov

Online ordering: http://www.ntis.gov/ordering.htm

OR

Lawrence Livermore National Laboratory

Technical Information Department's Digital Library

http://www.llnl.gov/tid/Library.html 


\title{
Injector-amplifier design for tabletop Ne-like x-ray lasers
}

\author{
J. Dunn ${ }^{\text {a }}$, A.L. Osterheld ${ }^{\text {a }}$, A. Ya. Faenov ${ }^{b}$, T.A. Pikuz ${ }^{\text {b }}$, and V.N. \\ Shlyaptsev ${ }^{\mathrm{C}}$ \\ 'Lawrence Livermore National Laboratory, Livermore, CA 94551-9900 \\ ${ }^{\mathrm{b}}$ Multicharged Ions Spectra Data Center of VNIIFTRI, Mendeleevo, \\ Moscow Region 141570 Russia \\ ${ }^{c}$ University of California Davis-Livermore, Livermore, California 94551
}

\begin{abstract}
We report new results using the LLNL COMET laser to evaluate the effectiveness of different target architectures to improve the output and characteristics of the transient $\mathrm{x}$-ray laser scheme. Surprising observations were found when the laser line focus irradiating a single slab $\mathrm{Cr}$ or Fe target was divided into two or three distinct plasma column sections with millimeter scale gaps between each plasma. The Ne-like $3 \mathrm{p}^{\prime} \mathrm{S}_{0} \rightarrow 3 \mathrm{~s}{ }^{1} \mathrm{P}_{1} 28.5 \mathrm{~nm}$ and $25.5 \mathrm{~nm}$-ray laser lines, for $\mathrm{Cr}$ and $\mathrm{Fe}$, respectively, were improved in beam divergence, by $2-3$ times, and peak intensity, by up to one order of magnitude, when compared with a single plasma column of the same length or longer. This was contrary to expectations since these large-scale inhomogeneities introduced along the plasma, as well as attenuation from the cold plasma at the end of each section, would be detrimental to the $\mathrm{x}$-ray propagation and amplification. Instead an injectoramplifier (IA) type process appears to be at work where the plasma gaps may be beneficially modifying the ray propagation and coupling through the high Ne-like ion gain regions. We present results showing the output of the amplifier stage with increasing length for the IA targets together with beam deflection and divergence measurements.
\end{abstract}

\section{INTRODUCTION}

The use of oscillator-amplifier or injector-amplifier designs, i.e. multiple- instead of single-stage designs, have been suggested as one way to improve the output characteristics for large, high power, laser-generated x-ray lasers. An injector-amplifier (IA) architecture was proposed in order to improve the output coherence by seeding an amplifier with a single-mode from an oscillator or injector [1]. Preliminary experiments investigating this effect on the NOVA laser were reported approximately 10 years ago [2]. Another important reason for using IA design was to mitigate against refraction effects bending the $\mathrm{x}$-ray laser beam out of the gain region when target

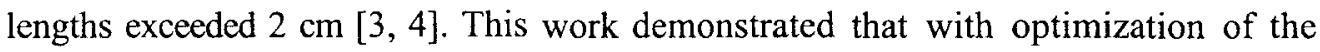
target offset, the coupling efficiency between the two stages was maximized and the effect of refraction was reduced. More recently hybrid oscillator-amplifier schemes have been proposed by using higher order harmonics as a seed to be amplified in a fast capillary discharge gain medium [5] or a picosecond-heated solid target [6]. 
In many respects, the high efficiency, transient gain, tabletop $\mathrm{x}$-ray lasers can also benefit from injector-amplifier designs. While the required target lengths for saturated output are considerably shorter, typically less than $1 \mathrm{~cm}$, refraction can still be a limiting effect because of the extremely high gains, $\mathrm{g}>100 \mathrm{~cm}^{-1}$, available in higher density regions [7]. Small deflection angles of the $x$-ray laser beam out of these regions may reduce the gain by $10-20 \%$ or more which is sufficient to substantially decrease the $\mathrm{x}$-ray laser output over a few millimeters of plasma length.

We report experimental results from a very simple approach where a single, flat slab target has been irradiated with two or three shorter line foci produced by placing a mask in the focusing beam. The millimeter-scale gaps in the line focus form multiple stages in the plasma column and are observed to substantially improve the beam divergence and intensity of several Ne-like ion x-ray lasers.

\section{EXPERIMENTAL DESCRIPTION}

The experiment was carried out on the Compact Multipulse Terawatt (COMET) laser system at LLNL [8]. This laser, operating at $1054 \mathrm{~nm}$ wavelength, utilizes chirped pulse amplification to produce the two laser beams to generate the $\mathrm{x}$-ray laser. For this study on Ne-like $\mathrm{Cr}$ and Fe x-ray lasers, energy of $0.6-4.8 \mathrm{~J}$ in a $600 \mathrm{ps}$ pulse was followed by a delay of $1.4 \mathrm{~ns}$ before utilizing a $1.2 \mathrm{ps}$ excitation pulse with $5 \mathrm{~J}$. The laser repetition rate was 1 shot every 4 minutes. The line focus length of 1.1 $\mathrm{cm}$ was achieved with a cylindrical lens and an on-axis paraboloid. The $600 \mathrm{ps}$ beam was defocused to a width of $\sim 150 \mu \mathrm{m}$ (FWHM) while the $1.2 \mathrm{ps}$ beam was focused to $80 \mu \mathrm{m}$ [9]. A simple reflection echelon technique was adopted to produce a traveling wave line focus as described in previously related $x$-ray laser work [10]. The traveling wave optic consisted of five flat mirror segments placed before the focusing optics where each mirror segment was offset by $0.12 \mathrm{~cm}$ to introduce a traveling wave towards the spectrometer with a delay of 7.7 ps per step. This corresponded to a phase velocity of $c$ along the line focus length with five steps.

The on axis $\mathrm{x}$-ray laser output was observed with a 1200 line $\mathrm{mm}^{-1}$ variable-spaced flat-field grating spectrometer with a back-thinned $1024 \times 1024$ charge-coupled device (CCD). A $1 \mu \mathrm{m}$ thick Al filter, determined to have a filter transmission of 0.032 at $28.54 \mathrm{~nm}$, was used at highest $\mathrm{x}$-ray laser intensities to prevent the CCD from saturating. Fiducial wires, placed in front of the spectrometer, were aligned relative to the target surface with a telescope in order to calibrate the angular deflection and beam divergence of the $\mathrm{x}$-ray laser in the horizontal direction. Flat polished $\mathrm{Cr}$ and $\mathrm{Fe}$ slab targets were used in the experiment and tilted back by $\sim 5 \mathrm{mrad}$ in the horizontal direction to compensate for refraction of the $x$-ray laser in the plasma column. A CCD $\mathrm{x}$-ray double-slit camera with $25 \mu \mathrm{m}$ spatial resolution monitored the line focus plasma uniformity and overlap of the laser pulses. In addition to these diagnostics, several Focusing Spectrometers with Spatial Resolution in 1-Dimension (FSSR-1D) 
instruments using Kodak DEF film and CCD detector arrays were employed [11]. These gave $n=3 \rightarrow 2,4 \rightarrow 2 \mathrm{Ne}$-like $\mathrm{Fe}$ and $\mathrm{Cr}$ resonance line emission measurements with spatial information along the length of the laser line focus.

(a)

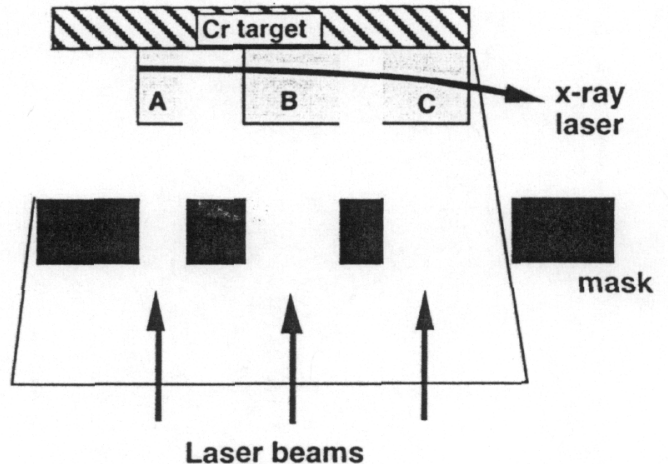

(b)

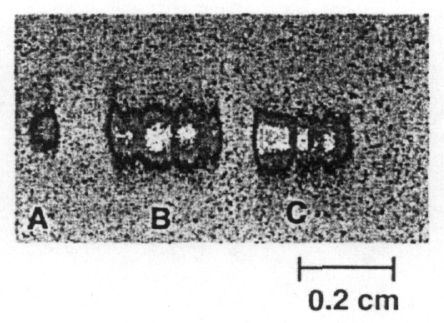

Fig. 1 (a) A mask placed in focusing beam generates three-stages A, B, and C along the $\mathrm{Cr}$ plasma. (b) X-ray double-slit camera image of $\mathrm{X}$-ray emission showing three $\mathrm{Cr}$ stages clearly visible in the line focus. Magnification is $1 \times$ along the focus length and $14 x$ across the focus width.

To compare the effect of the multi-stage target to the single stage target, it was important to maintain the same line intensity along the line focus but with the gaps. Although it would have been possible to create gaps in the line focus by simply separating the segments using the traveling wave stepped mirror, this may have changed the longitudinal intensity profile. Instead an alternative method was tried where a mask was placed in the focusing beam about $12 \mathrm{~cm}$ from the target. This created small gaps of approximately $1 \mathrm{~mm}$ length with minimal diffraction effects on the line focus. Figure 1 shows this experimental layout. The x-ray laser output could be studied with and without the gaps. A two-stage device was tried for Fe and a threestage for the $\mathrm{Cr} \mathrm{x}$-ray laser with similar results. We report on a three-stage $\mathrm{Cr} \mathrm{x}$-ray laser using a $1 \mathrm{~cm}$ target irradiated with $\sim 3 \mathrm{~J}, 600 \mathrm{ps}$ and $4.8 \mathrm{~J}, 1.2 \mathrm{ps}$.

\section{EXPERIMENTAL RESULTS}

The conventional single-stage $\mathrm{Cr}$ targets have been reported recently [9]. Strong lasing was observed on the $28.54 \mathrm{~nm} 3 p \rightarrow 3 s$ line, with weaker lasing on both the $25.91 \mathrm{~nm} 3 d \rightarrow 3 p$ line and the short wavelength $24.03 \mathrm{~nm} 3 p \rightarrow 3 s$ line. An intensity versus length study was performed for single-stage target lengths of $0.2 \mathrm{~cm}$ to $1 \mathrm{~cm}$, and small-signal gain of $31 \mathrm{~cm}^{-1}$ was determined for the $28.54 \mathrm{~nm} 3 p \rightarrow 3 s$ line for targets up to $0.4 \mathrm{~cm}$. The output was found to increase at a lower exponential rate up to $1 \mathrm{~cm}$. The overall gain length product of $16.7 \pm 0.6$ was above the predicted saturation intensity. Using this as a reference for single-stage $\mathrm{Cr}$ target output, the mask was placed in the beam to generate the three-stage target, as shown in Fig. 1. Similar laser pumping conditions were repeated. The $\mathrm{x}$-ray laser intensity was found to be substantially higher for the combined lengths of the three stages when compared 


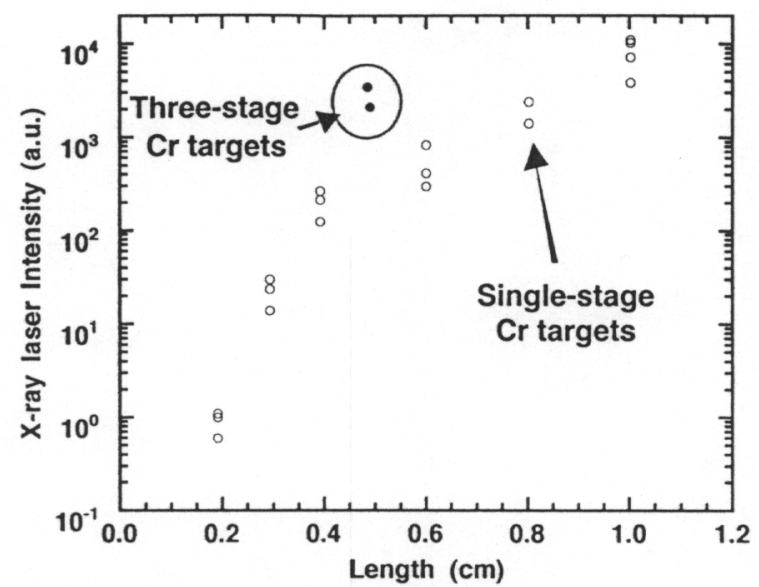

Fig. $2 \mathrm{X}$-ray laser output of the $\mathrm{Cr} 38.5 \mathrm{~nm} 3 p \rightarrow 3 s$ line as a function of target length for $\mathrm{Cr}$ single-stage (open circles) and three-stage targets (closed circles). Note that the three-stage target length is the combined length of all three stages as determined by the double-slit $\mathrm{x}$-ray imaging camera.

with a single stage length. This is shown in Fig. 2 where the three-stage Cr target for $0.5 \mathrm{~cm}$ is higher than a $0.8 \mathrm{~cm}$ single-stage. For this situation, a close proximity injector-amplifier action is proposed as the explanation for the enhanced output of the multi-stage target. For nomenclature purposes, the first two stages, A and B in Fig. 1, are considered as the injector and stage $\mathrm{C}$ as the amplifier.

(a)

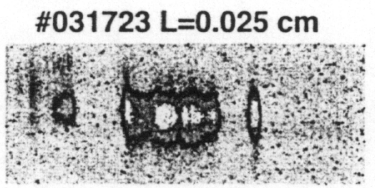

(b)

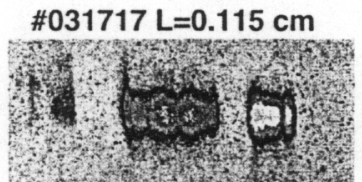

(c)

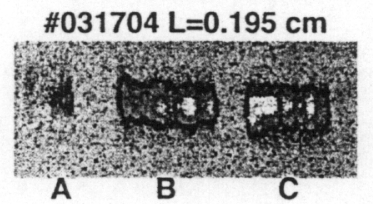

(d)

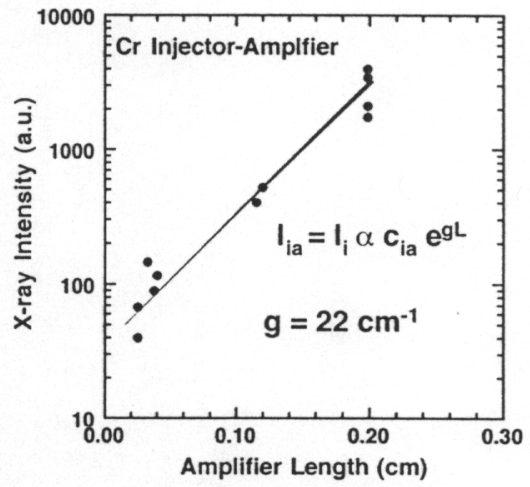

Fig. 3 (a), (b), (c) are x-ray images of the line focus where the amplifier section length, $L$, is varied from $0.025,0.115$ and $0.195 \mathrm{~cm}$, respectively. (d) The x-ray laser output intensity of the Cr $28.5 \mathrm{~nm}$ line plotted as a function of amplifier length, $L$.

The length of the amplifier section, up to a maximum of $0.2 \mathrm{~cm}$, could be varied by moving the target longitudinally in the line focus. The injector stage length (A and B) remained constant and it was possible to measure the total output from stage $B$, and 
therefore the injector intensity $I_{i}$ coupled into the amplifier stage. Stage A length, a single-stage, was less than $0.1 \mathrm{~cm}$ and the output intensity was too low to measure. Figures 3(a) - (c) show x-ray double-slit images of the line focus plasma where the amplifier stage is being varied in length. The corresponding $x$-ray laser intensity of the $\mathrm{Cr} 28.5 \mathrm{~nm}$ line is plotted as a function of the amplifier length, Fig. 3(d). It would be expected that the injector-amplifier output, $I_{i a}$, can be written as $I_{i a}=I_{i} \alpha c_{i a} e^{g L}+I_{a}$ where $I_{i}$ is the injector output, $\alpha$ the attenuation from cold plasma at the end of the injector and amplifier stages, $c_{i a}$ coupling efficiency from injector to amplifier stages, $g$ the small signal gain for ampiifier length $L$, and $I_{a}$ is the unseeded amplified spontaneous emission (ASE) from the amplifier stage. From Fig. 2 the ASE from a 0.2 $\mathrm{cm}$ target is $\sim 1$ count and so all of the amplifier output is due to seeding. The average small signal gain is estimated to be $\sim 22 \mathrm{~cm}^{-1}$.

(a)

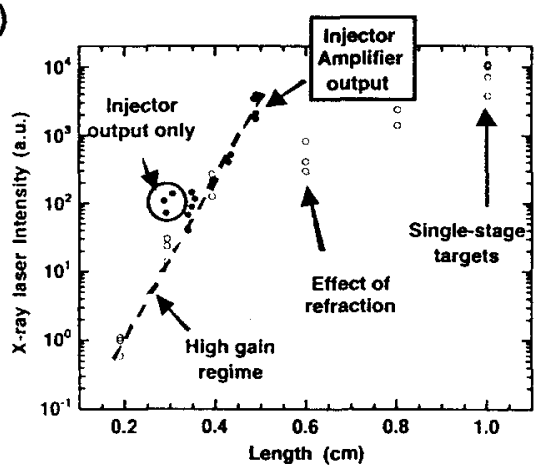

(b)

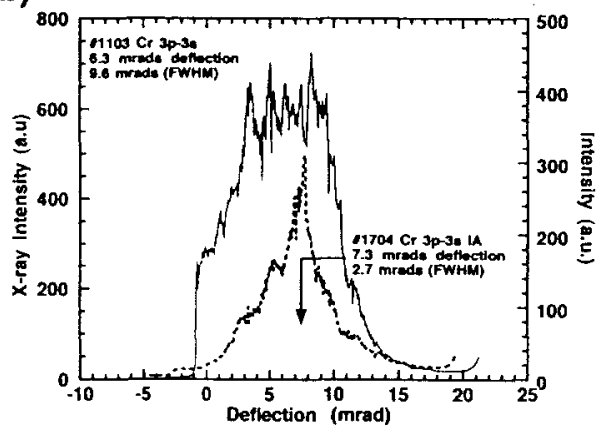

Fig. 4 (a) $\mathrm{Cr} \mathrm{x}$-ray laser intensity plotted against length for single-stage and multi-stage targets. (b) Angular pointing of a $1 \mathrm{~cm}$ single-stage plotted with a $0.5 \mathrm{~cm}$ multi-stage target.

Figure 4(a) shows the multi-stage output plotted together with the single-stage data. The overall output of the $0.5 \mathrm{~cm}$ multi-stage while not exceeding the $1 \mathrm{~cm}$ single stage output has an estimated gain length product of 15 and is close to saturation. Figure 4(b) shows the pointing angle and beam divergence of a $1 \mathrm{~cm}$ single-stage target and multi-stage $0.5 \mathrm{~cm}$ target. The single-stage deflection angle and beam divergence are similar to previous results for $\mathrm{Ti}[12,13]$. The multi-stage target although shorter has a substantially narrower beam divergence angle. Typically $2-3$ times narrower beam divergence for the multi-stage targets was observed.

\section{DISCUSSION}

This simple injector-amplifier target architecture consisting of multiple stages demonstrates improved $x$-ray characteristics in beam divergence and output mainly by mitigating the effects of refraction, to be modeled in simulations. It was expected that the large scale non-uniformities in the line focus would be substantially detrimental to the $\mathrm{x}$-ray laser propagation along the plasma column. This has not been the case and 
raises the question of beam uniformity in transient gain $\mathrm{x}$-ray lasers. Secondly, at the ends of each stage regions of cold plasma will be created resulting in absorption losses by free-free inverse bremsstrahlung or photo-ionization of low $\mathrm{Pd}$ charge states. However, even though this setup is not ideal, the effect of creating a multiple stage target appears to maintain the $\mathrm{x}$-ray laser propagating through the high gain region, Fig. 4(a), without the roll-off that affects single targets of length greater than $0.4 \mathrm{~cm}$. The large spatial extent of the Ne-like gain region away from the target is expected to be important for this scheme.

\section{ACKNOWLEDGMENTS}

The authors would like to thank Jim Hunter for technical support in this research. This work was performed under the auspices of the US Department of Energy by the University of California Lawrence Livermore National Laboratory under Contract No. W-7405-Eng-48.

\section{REFERENCES}

1. M.D. Rosen, J.E. Trebes, and D.L. Matthews, Comments Plasma Phys. Controlled Fusion 10, pp. 245 - 252 (1987).

2. G.M. Shimkaveg et al., in X-ray Lasers 1992, edited by E.E. Fill, IOP Conference Series 125 , Bristol and Philadelphia, 1992, pp.61 - 66.

3. C.L.S. Lewis, D. Neely, D.M. O’Neill, J.O. Uhomoibhi, M.H. Key, Y. Al Hadithi, G.J. Tallents, and S.A. Ramsden, Optic. Comm. 91, pp. 71-76 (1992).

4. S. Wang et al., J. Opt. Soc. Am. B. 9, pp. 360-368 (1992).

5. J.J. Rocca, J.L.A. Chilla, S. Sakadzic, A. Rahman, J. Filevich, E. Jankowska, E.C. Hammarsten, and B. Luther, in "Soft $x$-ray Lasers and Applications IV", ed. E.E. Fill and J.J. Rocca, SPIE Proc. 4505, pp. 1-6 (2001).

6. N. Hasegawa, A.V. Kilpio, K. Nagashima, T. Kawachi, M. Kado, M. Tanaka, S. Namba, K. Takahashi, K. Sukegawa, P. Lu, H. Tang, M. Kishimoto, R. Tai, H. Daido, Y. Kato, ibid. 4505, pp. 204-210 (2001).

7. V.N. Shlyaptsev P.V. Nickles, T. Schlegel, M.P. Kalahnikov, and A.L. Osterheld, in "Ultrashort Wavelength Lasers", ed. S. Suckewer, SPIE Proc. 2012, pp. 111-118 (1993).

8. J. Dunn, J. Nilsen, A.L. Osterheld, Y. Li, and V.N. Shlyaptsev, Opt. Lett. 24, pp. 101-3 (1999).

9. J. Dunn et al., in "X-ray Lasers 2000 ", $7^{\text {th }}$ International conference on X-ray Lasers, St. Malo, France June 19 - 23, ed. G. Jamelot, C. Möller, A. Klisnick, J.Phys. IV 11, Pr2-19 (2001).

10. J.R. Crespo et al, Proc. SPIE Int. Soc. Opt. Eng. 2012, pp.258-264 (1993).

11. A.Ya. Faenov, S.A. Pikuz, A.I. Erko, B.A. Bryunetkin, V.M. Dyakin, G.V. Ivanenkov, A.R. Mingaleev, T.A. Pikuz, V.M. Romanova, T.A. Shelkovenko. Phys. Scr. 50, pp. 333 (1994).

12. M.P. Kalachnikov, P.V. Nickles, M. Schnürer, W. Sandner, V.N. Shlyaptsev, C. Danson, D. Neely, E. Wolfrum, J. Zhang, A. Behjat, A. Demir, G.J. Tallents, P.J. Warwick, and C.L.S. Lewis, Phys. Rev. A 57, pp. $4778-4783$ (1998)

13. J. Dunn, A.L. Osterheld, Y. Li, I. Nilsen, and V.N. Shlyaptsev, in "Short Wavelength Lasers and Applications", ed. J.G. Eden and J.J. Rocca, IEEE Journal of Selected Topics in Quantum Electronics 5(6), 1441 - 1446(1999). 